\title{
Magnetic Anomalies Related to Active Folds in the North Anatolian Fault Zone
}

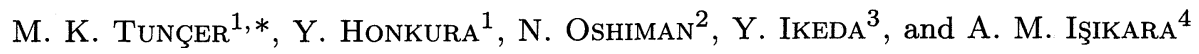 \\ ${ }^{1}$ Department of Applied Physics, Tokyo Institute of Technology, Tokyo, Japan \\ ${ }^{2}$ College of Humanities and Sciences, Nihon University, Tokyo, Japan \\ ${ }^{3}$ Department of Geography, University of Tokyo, Tokyo, Japan \\ ${ }^{4}$ Department of Geophysics, Boğaziçi University, Istanbul, Turkey
}

(Received April 27, 1990; Revised July 4, 1991)

\begin{abstract}
Measurements of the geomagnetic total intensity were carried out in the western part of the North Anatolian Fault Zone. In particular, profile measurements were made across some fold structures in the graben. The data show anomalies presumably related to active folds, although fold structures are not necessarily accompanied by magnetic anomalies. The anomalies are similar to those found along the active faults in the North Anatolian Fault Zone, and they could be interpreted in terms of a dike-like structure model as was the case for the anomalies associated with the active faults. This implies that folding may be a surface manifestation of faulting at depth.
\end{abstract}

\section{Introduction}

The North Anatolian Fault Zone (NAFZ) is a $1500 \mathrm{~km}$ long transform fault, and many right-lateral strike-slip faults exist in the zone. Its overall activity has been considered as direct evidence of relative motion between the Anatolian block and the Black Sea plate. Large destructive earthquakes have occurred repeatedly in the past along this fault zone (AMBRASEYs, 1970). The westward extension of NAFZ branches off at $30.6^{\circ} \mathrm{E}$ into two active fault zones, the northern and southern branches (e.g. DEWEY and ŞENGÖR, 1979; BARKA and HANCOCK, 1984; HERECE, 1985; BARKA and KADINSKY-CADE, 1988).

The northern branch constitutes a graben-like structure which is filled with Cenozoic sediments and is characterized by an extensional tectonic stress regime. As will be shown in the next section, many active fold structures have been found in the graben, although fold structures obviously imply compressional stress and disagree with the extensional stress regime (IKEDA et al., 1989).

The magnetic anomalies found near the active fault constituting the southern branch could be well interpreted in terms of a dike-like structure, which in turn provided information on the surface extension of the fault plane as well as its dip angle (HONKURA et al., 1985; IŞIKARA et al., 1985). Folding may also disturb the subsurface magnetic structure and yield a magnetic anomaly to be observed at the Earth's surface.

* Present address: Department of Geophysics, Boğaziçi University, Istanbul, Turkey. 
This is the motivation of our measurements of the geomagnetic total intensity in the northern branch of NAFZ.

\section{Tectonic Setting}

Tectonic characteristics of the northern branch of NAFZ have been discussed frequently by many authors (e.g. ŞENGÖR et al., 1982; SiPAHIOĞLU and MATSUDA, 1986; IKEDA, 1988; IKEDA et al., 1989). The Izmit-Sapanca fault zone, the northern branch of NAFZ as shown in Fig. 1, is a sedimentary trough as wide as 5-8 km. This portion of NAFZ is believed to be a transition zone from dominantly transcurrent motion in the east to the extensional tectonic regime in western Turkey and the Agean Sea (DEWEY and ŞENGÖR, 1979; MCKEnZIE, 1972; EvANS et al., 1985). Focal mechanism solutions for microearthquakes occurring in the Izmit-Sapanca fault zone suggest that transtensional movements are dominant (EvANs et al., 1985).

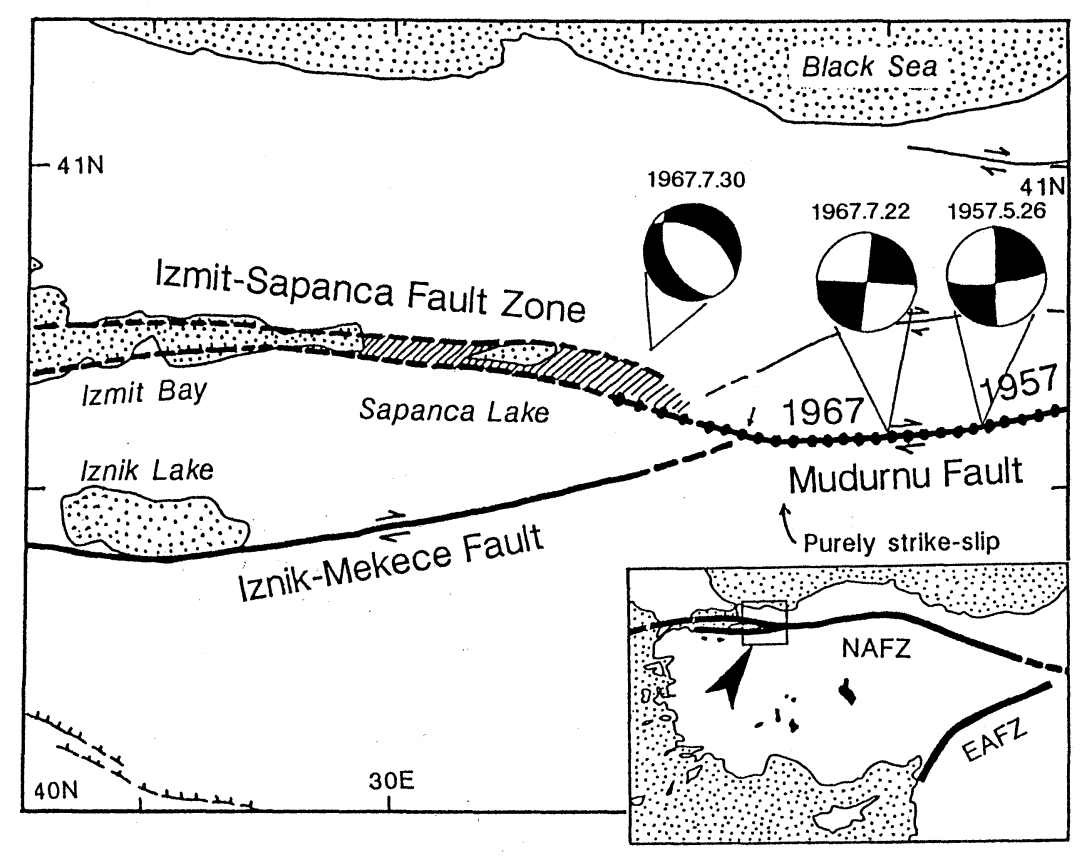

Fig. 1. Tectonic sketch map showing main characteristics of the westernmost portion of the North Anatolian Fault Zone (NAFZ). NAFZ west of $30.6^{\circ} \mathrm{E}$ branches into two fault zones; the IzmitSapanca fault zone and the Iznik-Mekece fault. Surface raptures along the Mudurnu fault in association with the earthquakes of May 26, 1957 and July 22, 1967 are indicated by small dots (after AMBRASEYS and ZAPOTEK, 1969; AMBRASEYS, 1970). Focal mechanisms of these two earthquakes and the largest aftershock (July 30, 1967) of the July 22, 1967 earthquake are also shown (after MCKEnZIE, 1972).

In the meantime, IKEDA et al. (1989) found some lines of evidence showing that the sediments filling the trough have been subjected to compressional deformation. 


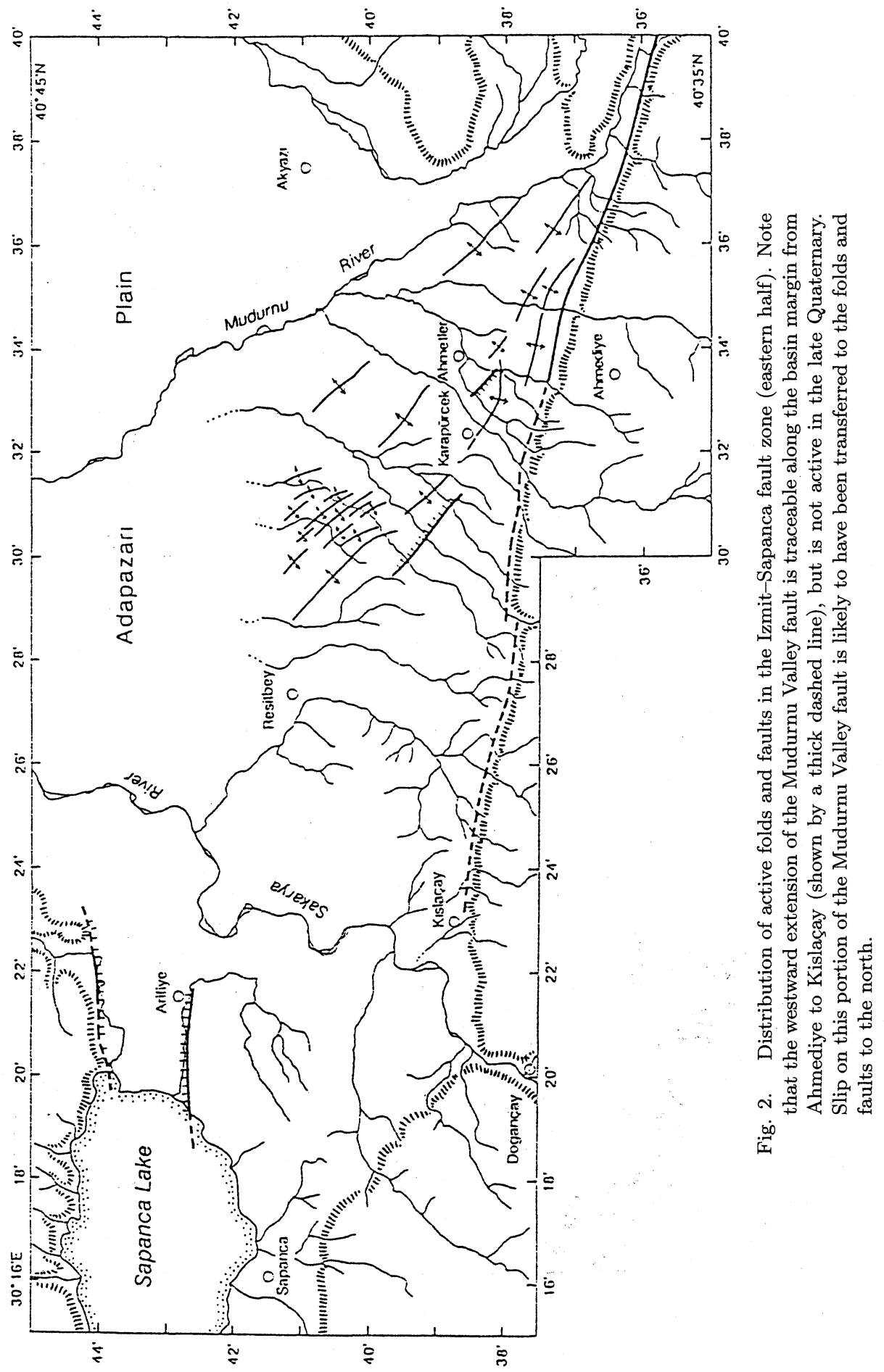




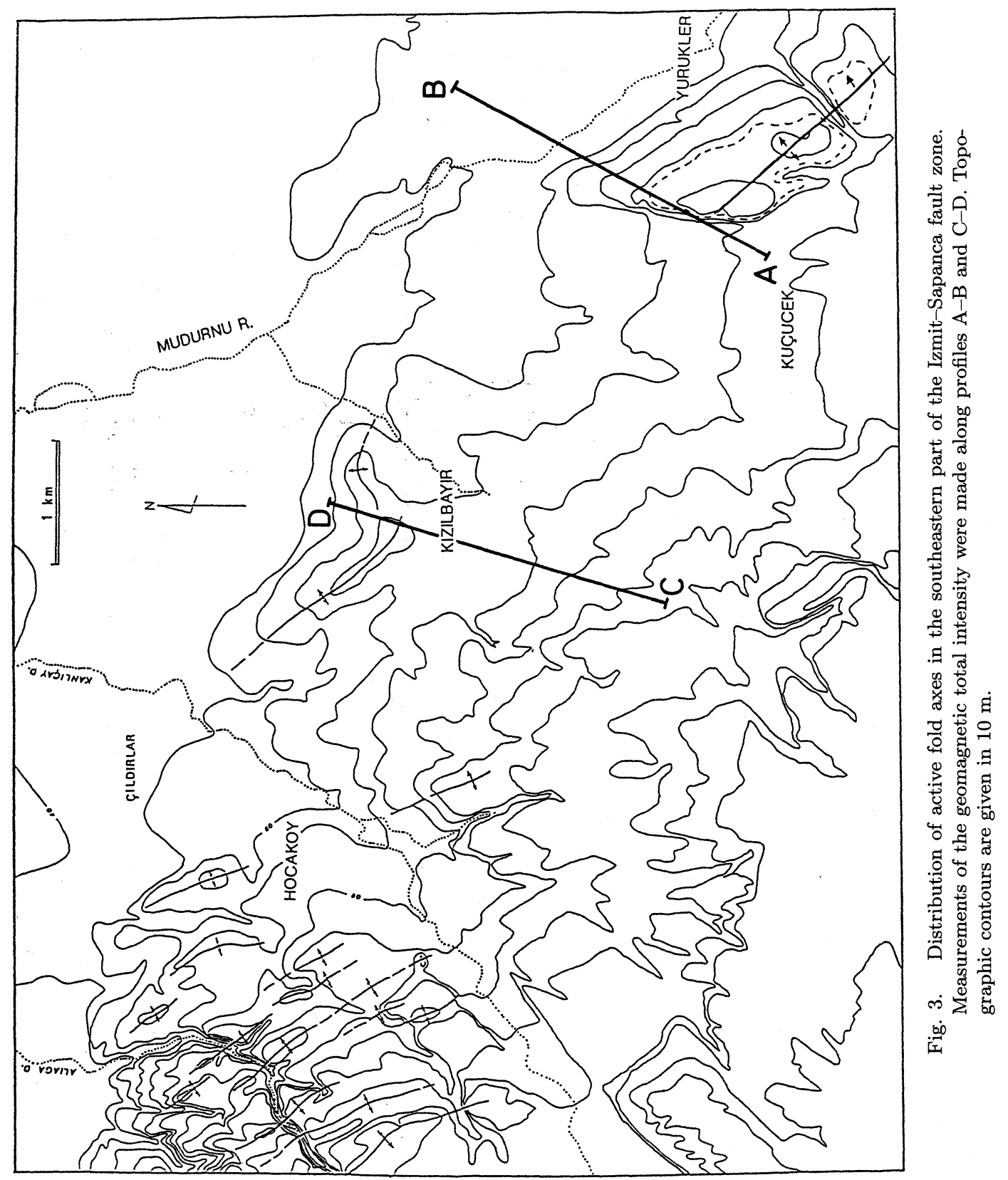


Figures 2 and 3 show the distribution of active faults and folds. In particular, we should note many active folds in the Izmit-Sapanca fault zone, although we will not enter into details; more discussions are beyond our present scope and geomorphological information will be given elsewhere (Ikeda et al., in preparation). Contradiction between compressional stress as implied by the geomorphologically inferred fold structures, and extensional stress as indicated by focal mechanism solutions, and also by the overall geological structure, should have a very important bearing on tectonics in this region. Information on the subsurface structure must be one of the essential points in this problem.

\section{Measurements of the Geomagnetic Total Intensity}

Figure 3 also shows two profiles, along which the geomagnetic total intensity was measured, in the area east of the Sapanca Lake, whereas Fig. 4 shows a profile in the area west of the Sapanca Lake. We selected these profiles simply because magnetic measurements seemed to be easily made along a nearly straight line crossing the fold axis. Total intensity values are shown in Fig. 5; these values are relative to the total intensity at one of the continuous stations which have been in operation in the southwest of the present area, and daily variations are almost completely removed.

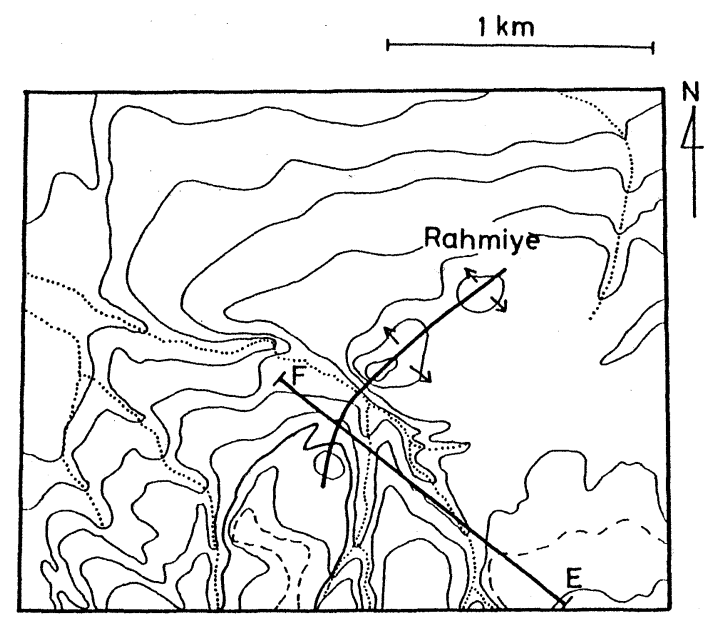

Fig. 4. Profile E-F for magnetic measurements and a fold axis at Rahmiye. Topographic contours are given in $10 \mathrm{~m}$.

In order to interpret these anomalies, we consider a two-dimensional inclined dikelike body. The two-dimensional treatment would be justified, because we deal with the fold structure which can be approximated by a two-dimensional feature. We used the method of calculation, originally proposed by TELFORD et al. (1976), which is also described in WON (1981) and IşIKARA et al. (1985). For calculations, we first made cubic-spline interpolation for the data gap due to power lines and a bridge and then took nine-point moving averages for $\mathrm{C}-\mathrm{D}$ (Kizilbayir) and $\mathrm{E}-\mathrm{F}$ (Rahmiye) profiles because small-scale fluctuations for these profiles obscure the overall trend. 
For these data, we applied a vertical dike model with appropriate parameter values and obtained an approximate model. Starting with this approximate model, we derived the best fit model by an iterative inversion scheme (WATANABE, 1984). Parameters to be determined are the magnetic susceptibility, the dip angle, the depth, the thickness, and the location of a dike relative to the profile. The normal value of the total intensity in the area is also taken as a parameter. Portions surrounding a dike-like structure is regarded as being non-magnetic and also the direction of magnetization is assumed to be the same as that of the ambient magnetic field of the Earth; in this region the inclination is about $55^{\circ}$.

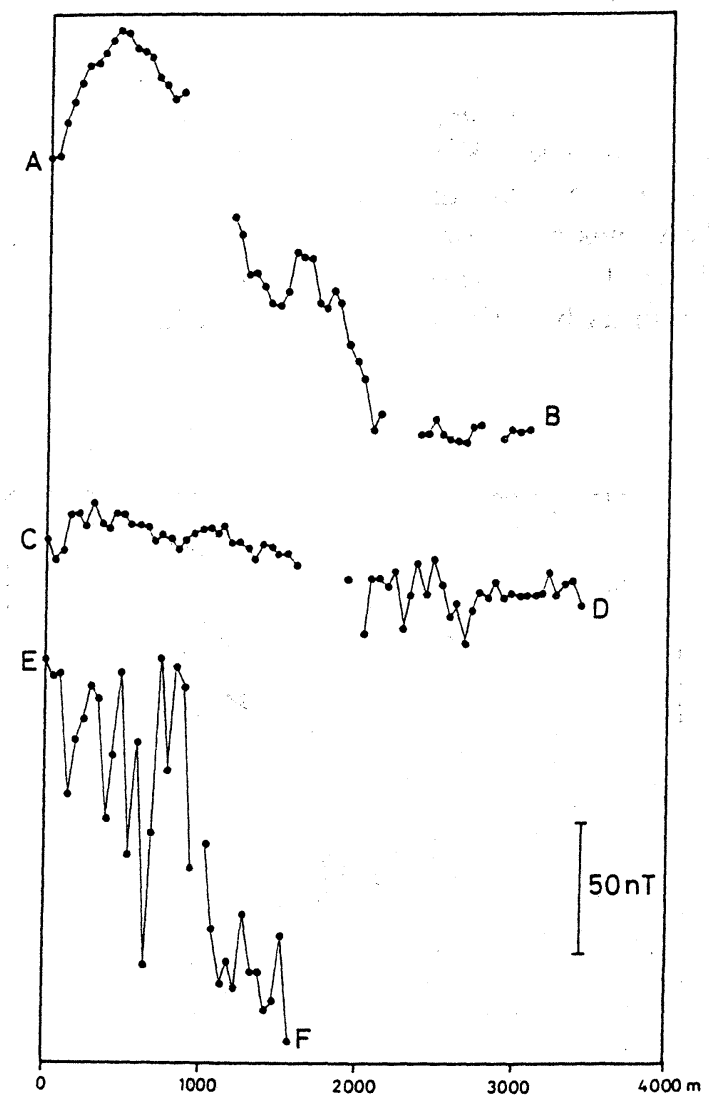

Fig. 5. The distribution of the geomagnetic total intensity along profiles A-B, C-D and E-F.

\subsection{Analysis of the magnetic anomaly observed at Küçücek}

The geomagnetic total intensity was measured along the profile $\mathrm{A}-\mathrm{B}$ as shown in Fig. 3. In the southeast, a topographic feature indicative of a fold structure was observed and the profile is likely to cross the fold axis. The data obtained at Küçücek are shown in Fig. 5. The distribution of the total intensity shows a positive peak and its location is close to the fold axis as shown in Fig. 4. The result of the iterative 
inversion analysis for this profile is seen in Fig. 6. The rms error for the model which can best explain this anomaly is about $10 \mathrm{nT}$. It turns out that a magnetic body having a susceptibility of $6.37 \times 10^{-4} \mathrm{emu} / \mathrm{cm}^{3}$ exists at a depth of about $300 \mathrm{~m}$ and dips to the southwest with the angle of $54^{\circ}$. The thickness is insignificant and the northeastern boundary can extend further to the northeast.

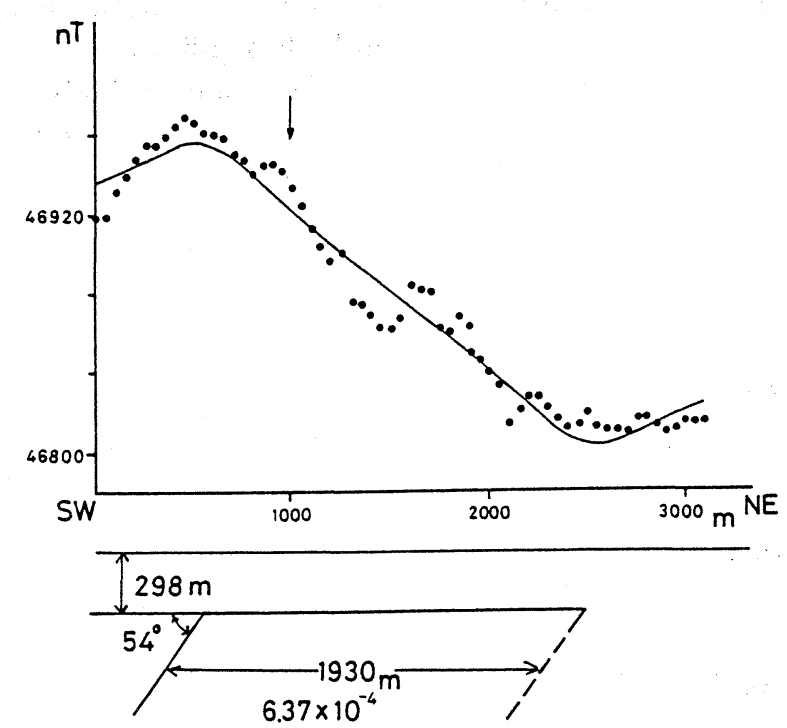

Fig. 6. Geomagnetic total intensity values (dots) observed at Küçücek and the distribution of the total intensity (solid line) derived from the best fit 2-D magnetic dike-like structure model. The arrow indicates the fold axis.

We examined the reliability of the estimated parameters by changing one specific parameter value with the others fixed at the values for the optimum model. If a residual twice as large as the one for the optimum model is considered allowable, a change of $20 \sim 30 \%$ is acceptable for the susceptibility, $10 \sim 15^{\circ}$ for the dip angle, $100 \sim 200 \mathrm{~m}$ for the boundary location. The depth is not well constrained if the optimum depth is greater than a few hundred meters. The dip angle is fairly reliable and hence useful for discussing the fault structure. The boundary location is also well constrained, since misfits for models deviated from the optimum model are overall shifts and such models are hardly acceptable as reliable ones. The extension of the southwestern boundary of the magnetic body to the surface seems to correspond to the fold axis shown by the arrow in Fig. 6. We here interpret the southwestern boundary as indicating a fault plane and then the fold structure at the surface can be considered to be a manifestation of undulatory deformation, caused by fault displacement, in a rather thick sedimentary layer. 


\subsection{Analysis of the magnetic anomaly observed at Kizilbayir}

The total intensity was measured along the profile C-D as shown in Fig. 3, about $3.5 \mathrm{~km}$ west of Küçücek. The data obtained at Kizilbayir are shown in Fig. 5. The model derived from the iterative inversion analysis for this profile is shown in Fig. 7. For this profile, the rms error is about $1.3 \mathrm{nT}$. The magnetic body is located at the depth of about $360 \mathrm{~m}$, but this estimate is not well constrained. Its susceptibility is fairly low amounting only to $1.13 \times 10^{-4} \mathrm{emu} / \mathrm{cm}^{3}$. It dips to the northeast with the angle of $67^{\circ}$. The thickness of the body is also determined from the inversion scheme, but the southwestern boundary is obviously of little significance.

In this case, the northeastern boundary of the magnetic body coincides with the fold axis shown by the arrow in Fig. 7. This is another example showing a possible association of a surface fold structure with a fault at depth.

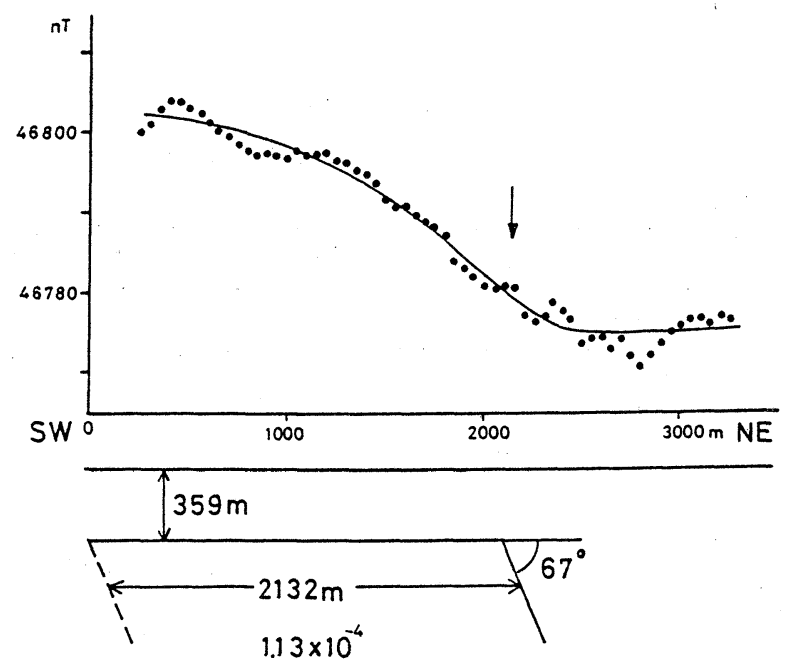

Fig. 7. Nine-point running averages of the geomagnetic total intensity (dots) observed at Kizilbayir and the distribution of the total intensity (solid line) derived from the best fit 2-D magnetic dike-like structure model. The arrow indicates the fold axis.

\subsection{Analysis of the magnetic anomaly observed at Rahmiye}

The total intensity was also measured along the profile E-F shown in Fig. 8. The geomagnetic total intensity data obtained along the profile crossing the fold axis, which runs in the northeast-southwest direction, are shown in Fig. 5. The result of the iterative inversion analysis for this profile is shown in Fig. 8 together with the running average data. The rms error is about $5.6 \mathrm{nT}$. The magnetic body having a susceptibility of $5.05 \times 10^{-4} \mathrm{emu} / \mathrm{cm}^{3}$ is located at the depth of about $130 \mathrm{~m}$ and dips to the northwest direction. Again the southeastern boundary is meaningless.

In Fig. 8, the relation between the fold axis shown by the arrow and the northwestern boundary of the magnetic body is not very obvious, but a discrepancy of only a few hundred meters can be ascribed either to slight modification of surface topography or to poor resolution in magnetic modeling, or to both. 


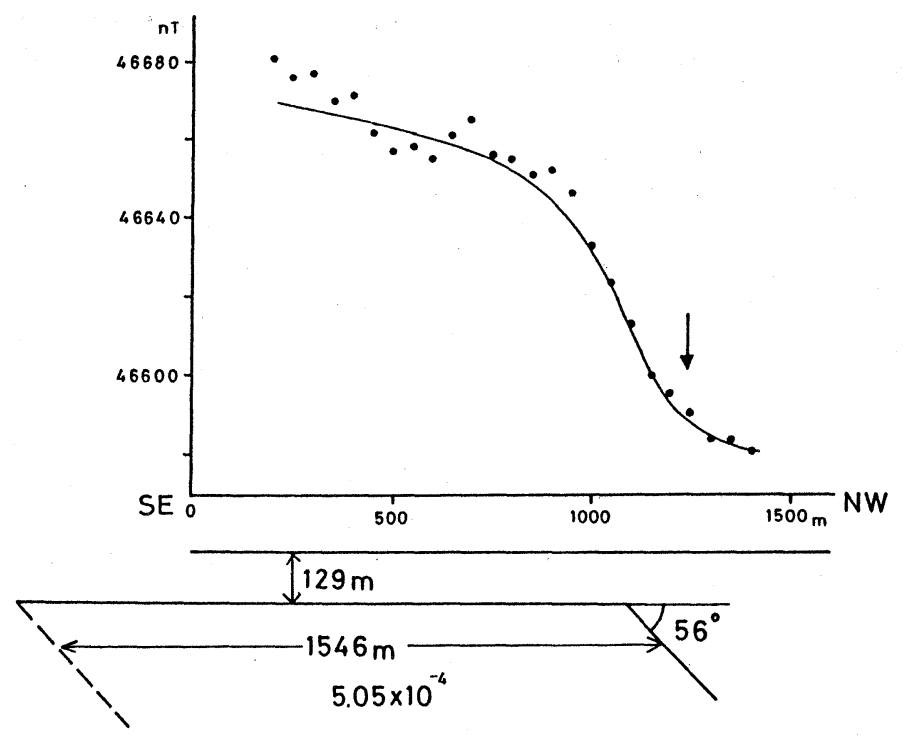

Fig. 8. Nine-point running averages of the geomagnetic total intensity (dots) observed at Rahmiye and the distribution of the total intensity (solid line) derived from the best fit 2-D magnetic dike-like structure model. The arrow indicates the fold axis.

\section{Discussion and Concluding Remarks}

We have shown the results of geomagnetic total intensity measurements in the northern branch of the North Anatolian Fault Zone. In this area, some magnetic anomalies seem to be related to fold structures. However, fold structures are not necessarily accompanied by magnetic anomalies; in fact, no notable magnetic anomaly was found from measurements of the geomagnetic total intensity which were made along a profile crossing many fold axes shown in the northwest corner of Fig. 3. We can easily attribute such a case to weak magnetization of basement rocks. They are unlikely to yield a significant magnetic anomaly even if they are affected by faulting or folding.

At first we may ascribe the magnetic anomalies to an undulatory magnetic layer associated with folding, but the typical scale length is different and this possibility is ruled out. Magnetic anomalies observed at Küçücek, Kizilbayir and Rahmiye were all interpreted rather in terms of a dike-like structure, although one of the boundaries of the model structure is insignificant and may be extended further away. We further interpret the boundary as indicating a fault plane. In order for a fault displacement beneath the sedimentary layer to result in a fold structure at the surface of the layer, the topographically lower side should be upheaved; fold structures shown in Figs. 3 and 4 can all be interpreted in such a way.

If the above condition is applied to the three fault models, the fault plane shown in Fig. 6 should represent normal faulting, whereas the planes shown in Figs. 7 and 8 should correspond to thrust faulting. Usually, surface folding can be associated with 
thrust faulting at depth (Stein and KInG, 1984; Stein and YeAts, 1989). The three cases shown above may not be an example of such a large-scale structure but rather a local phenomenon reflecting secondary deformation of sediments caused by faulting below the sediments.

Our interpretation of the magnetic anomalies related to surface fold structures indicates the existence of thrust faulting as well as normal faulting in the Izmit-Sapanca area. This interpretation agrees partly with the extensional stress regime and also partly with the compressional stress regime. This apparent contradiction may be understood if vertical displacement is secondary and a dominant feature is strike-slip movement. This is only a possibility and more studies are obviously needed to confirm this possibility.

We are thankful to the anonymous referees for their valuable comments. This work was supported by the Ministry of Education, Science and Culture, Japan, under International Scientific Research Program Nos. 61041029, 62043026, 63041054 and by Boğaziçi University under Project 88T0255.

\section{REFERENCES}

Ambraseys, N. N., Some characteristic features of the North Anatolian Fault Zone, Tectonophysics, 9, 143-165, 1970.

Ambraseys, N. N. and A. ZATOPEK, The Mudurnu valley, West Anatolia, Turkey, earthquake of 22 July 1967, Bull. Seismol. Soc. Am., 59, 521-589, 1969.

BARKA, A. A. and P. L. HANCOCK, Neotectonic deformation patterns in the convex-northwards arc of the North Anatolian Fault Zone, in The Geological Evolution of the Eastern Mediterranean, edited by J. G. Dixon and A. H. F. Robertson, pp. 763-774, Spec. Publ. Geol. Soc. London, 17, 1984.

BARKA, A. A. and K. KADINSKY-CADE, Strike-slip fault geometry and its influence on earthquake activity, Tectonics, 7, 663-684, 1988.

DEWEY, J. F. and A. M. C. ŞENGÖR, Agean and surrounding regions complex multi-plate and continuum tectonics in a convergent zone, Geol. Soc. Am. Bull., 90, 89-92, 1979.

Evans, R., S. Crampin, I. ASUDEH, and S. B. ÜGER, Tectonics of the Marmara sea region of Turkey; new evidence from micro-earthquake fault plane solutions, Geophys. J. Roy. astr. Soc., 83, 47-60, 1985.

HERECE, E. I., The Yenice-Gönen earthquake of 1953 and some examples of recent tectonic events in the Biga Peninsula of northwest Turkey, M.Sc. Thesis, Pennsylvania State Univ., 1985.

Honkura, Y., A. M. İ̧ikara, D. Kolçak, N. Orbay, S. SipahioĞLu, N. Oshiman, and H. Tanaka, Magnetic anomalies and low ground resistivity as possible indicators of active fault location: preliminary results of electric and magnetic observations from the western part of the North Anatolian Fault Zone, J. Geomag. Geoelectr., 37, 169-187, 1985.

IKEDA, Y., Geomorphological observations of the North Anatolian Fault Zone, west of Mudurnu, in Multidisciplinary Research on Fault Activity in the Western Part of the North Anatolian Fault Zone, edited by Y. Honkura and A. M. Işikara, pp. 6-14, 1988.

IKEDA, Y., Y. HONKURA, and A. M. IşIKARA, Quaternary compressional deformation in the IzmitSapanca trough, western Turkey, and its implications for the present tectonics near the western termination of the North Anatolian Fault Zone, in Multidisciplinary Research on Fault Activity in the Western Part of the North Anatolian Fault Zone (2), edited by Y. Honkura and A. M. Işikara, pp. 45-56, 1989.

IşiKara, A. M., Y. Honkura, N. Watanabe, N. Orbay, D. KolÇaK, N. Oshiman, O. GündoĞdu, and H. TANAKA, Magnetic Anomalies in the western part of the North Anatolian Fault Zone and their implications for the active fault structure, J. Geomag. Geoelectr., 37, 541-560, 1985. 
MCKenzie, D. P., Active tectonics of the Mediterranean region, Geophys. J. Roy. astr. Soc., 30, 109-185, 1972 .

Şengör, A. M., K. Burne, and J. F. Dewey, Tectonics of the North Anatolian transform fault, in Multidisciplinary Approach to Earthquake Prediction, edited by A. M. Işikara and A. Vogel, pp. 3-22, Friedr. Vieweg and Son, Braunschweig, 1982.

SipahioĞLu, S. and T. MATsudA, Geology and Quaternary fault in the Iznik-Mekece area, in Electric and Magnetic Research on Active Faults in the North Anatolian Fault Zone, edited by A. M. Işikara and Y. Honkura, pp. 25-41, 1986.

SteIn, R. S. and G. C. P. KING, Seismic potential revealed by surface folding: Coalinga, California, earthquake, Science, 224, 869-872, 1984.

Stein, R. S. and R. S. Yeats, Hidden earthquakes, Sci. Am., 260, No. 6, 30-39, 1989.

Telford, W. M., L. P. Geldart, R. E. SherifF, and D. A. Keys, Applied Geophysics, 860 pp., Cambridge Univ. Press, 1976.

Watanabe, N., Magnetic anomalies at active faults, Grad. Thesis, Tokyo Inst. Tech., 42 pp., 1984.

WoN, I. J., Application of Gauss's method to magnetic anomalies of dipping dikes, Geophysics, 46, 211-215, 1981. 